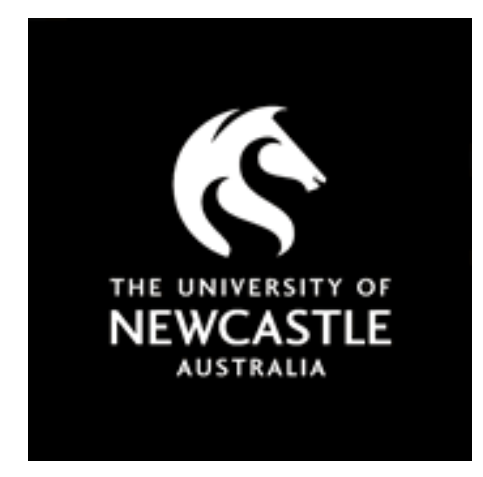

\title{
NOVA
}

University of Newcastle Research Online

nova.newcastle.edu.au

Riddell, Michael C.; Gallen, Ian W.; Annan, Francesca; Fournier, Paul A.; Graham, Claudia; Bode, Bruce; Galassetti, Pietro; Jones, Timothy W; San Millán, Iñigo; Heise, Tim; Peters, Anne L.; Petz, Andreas; Smart, Carmel E.; Laffel, Lori M.; Taplin, Craig E.; Adolfsson, Peter; Lumb, Alistair N.; Kowalski, Aaron; Rabasa-Lhoret, Remi; McCrimmon. Rory J.; Hume, Carin "Exercise management in type 1 diabetes: a consensus statement", Published in The Lancet Diabetes and Endocrinology Vol. 5, Issue 5, p. 377-390. (2017)

Available from: http://dx.doi.org/10.1016/S2213-8587(17)30014-1

(C) 2017 Elsevier. This manuscript version is made available under the CC-BY-NC-ND 4.0 license http://creativecommons.org/licenses/by-nc-nd/4.0/

Accessed from: http://hdl.handle.net/1959.13/1352933 


\section{Exercise management in type 1 diabetes: a consensus statement}

Michael C Riddell, Ian W Gallen, Carmel E Smart, Craig E Taplin, Peter Adolfsson, Alistair N Lumb, Aaron Kowalski, Remi Rabasa-Lhoret, Rory McCrimmon, Carin Hume, Francesca Annan, Paul A Fournier, Claudia Graham, Bruce Bode, Pietro Galassetti, Timothy W Jones, Inigo San Millan, Tim Heise, Anne Peters, Andreas Petz, Lori M Laffel

\begin{abstract}
Type 1 diabetes is a challenging condition to manage for various physiological and behavioural reasons. Regular exercise is important, but management of different forms of physical activity is particularly difficult for both the individual with type 1 diabetes and the health-care provider. People with type 1 diabetes tend to be at least as inactive as the general population, with a large percentage of individuals not maintaining a healthy body mass nor achieving the minimum amount of moderate to vigorous aerobic activity per week. Regular exercise can improve health and wellbeing, and can help individuals to achieve their target lipid profile, body composition, and fitness and glycaemic goals. However, several additional barriers to exercise can exist for a person with diabetes, including fear of hypoglycaemia, loss of glycaemic control, and inadequate knowledge around exercise management. This Review provides an up to date consensus on exercise management for individuals with type 1 diabetes who exercise regularly, including glucose targets for safe and effective exercise, and nutritional and insulin dose adjustments to protect against exercise-related glucose excursions.
\end{abstract}

\section{Introduction}

Despite tremendous advances since the discovery of insulin almost 100 years ago, management of type 1 diabetes remains challenging. ${ }^{1,2}$ The majority of patients living with type 1 diabetes do not have a healthy body weight (about $60 \%$ are overweight or obese), about $40 \%$ have hypertension, about $60 \%$ have dyslipidaemia, ${ }^{3}$ and most do not engage in enough regular physical activity. Regular exercise can help patients achieve several goals: it improves the cardiovascular disease risk profile in paediatric patients ${ }^{5}$ and reduces $\mathrm{HbA}_{1 \mathrm{c}}$ by about $0.3 \%$ in this [A: paediatric? Children and young people?] population [A: edits OK?]. ${ }^{6}$ Body composition, cardiorespiratory fitness, endothelial function, and blood lipid profile (ie, triglycerides and total cholesterol) all improve with regular physical activity in children and young people with type 1 diabetes.[A: ref 7 is a duplicate of ref 6; is this the correct ref, or did you want to cite a different ref here? References will be re-numbered as necessary $]^{7}$ These cardiometabolic improvements are all important, given that cardiovascular disease is the leading cause of morbidity and mortality in people [A: reference title refers to 'youth'. Correct reference here?] with type 1 diabetes. ${ }^{8}$ In adults, both retinopathy and microalbuminuria are less common in those who are physically active than in those who are not. ${ }^{9}$ Active adults with type 1 diabetes tend to have better chance of achieving their $\mathrm{HbA}_{1 \mathrm{c}}$ and blood pressure targets, and a healthier BMI, than do inactive patients. ${ }^{3}$ Regular exercise also decreases total daily insulin needs. ${ }^{10}$ Having a high exercise capacity in adulthood is associated with a reduced risk of coronary artery disease, myocardial ischaemia, and stroke, regardless of whether a person has diabetes or not. ${ }^{11}$ In a large cross-sectional study of 18028 adults with type 1 diabetes, ${ }^{3}$ patients who were categorised as being most physically active (exercising two or more times per week) had better $\mathrm{HbA}_{1 c}$ concentrations, a more favourable BMI, less dyslipidaemia and hypertension, and fewer diabetesrelated complications (retinopathy and microalbuminuria), than those who were less habitually active. In general [A: as you still refer to reference 3, would 'The study also showed that...' be more appropriate?], patients with type 1 diabetes who are more active tend to have less diabetic ketoacidosis and a reduced risk of developing severe hypoglycaemia with coma. ${ }^{3}$ However, older women who are physically active have higher rates of severe hypoglycaemia (with coma) than those who are inactive. Several barriers to exercise might exist, including a fear of hypoglycaemia, loss of glycaemic control, insufficient time, access to facilities, an absence [A:OK?] of motivation, issues around body image, and a general scarcity of knowledge around exercise management. ${ }^{12-14}$

For all adults living with diabetes, including those living with type 1 diabetes, 150 minutes of accumulated physical activity is recommended each week, with no more than two consecutive days of no physical activity [A: please give a reference for this sentence]. Resistance exercise is also recommended two to three times a week. Getting this much exercise is difficult for many patients; results from a large cross-sectional study showed that [A: insertion ok?] less than $20 \%$ of patients manage to do aerobic exercise more than two times per week, and about $60 \%$ of patients do no structured exercise at all. ${ }^{3}$ For children and young people, at least 60 minutes of physical activity should be done per day. ${ }^{15}$ Physical inactivity and prolonged sitting times increase gradually with age and are linked to high $\mathrm{HbA}_{1 \mathrm{c}}$ concentrations in young people with type 1 diabetes, ${ }^{16}$ and physical inactivity appears to be more common in women than in men. ${ }^{3}$

Regular exercise should be encouraged and supported by health-care professionals for many reasons, but primarily because the overall cardiometabolic benefits outweigh the immediate risks if certain precautions are
Lancet Diabetes Endocrinol 2017 [A: please check all affiliations carefully, provide highest degree for all authors, and indicate any full professors] Muscle Health Research Centre, York University, Toronto, ON, Canada (M C Riddell PhD); Royal Berkshire NHS Foundation Trust Centre for Diabetes and Endocrinology, Royal Berkshire Hospital, Reading, UK (I W Gallen); Hunter Medical Research Institute, School of Medicine and Public Health, University of Newcastle, Rankin Park, NSW, AustraliVa (CE Smart); Department of Paediatric Diabetes and Endocrinology, John Hunter Children's Hospital, Newcastle, NSW, Australia (CE Smart); Division of Endocrinology and Diabetes, Department of Pediatrics, University of Washington, Seattle Children's Hospital, Seattle, WA, USA (CE Taplin); Department of Pediatrics, The Hospital of Halland, Kungsbacka, Sweden (P Adolfsson); Institute of Clinical Sciences, Sahlgrenska Academy, University of Gothenburg, Gothenburg, Sweden (P Adolfsson); [PA: OK to split into two affiliations?] Oxford Centre for Diabetes, Endocrinology and Metabolism, Churchill Hospital, Oxford, UK (A N Lumb); Juvenile Diabetes Research Foundation, New York, NY, USA (A Kowalski); Department of Nutrition and Institut de Recherches Cliniques de Montréal, Faculty of Medicine, University of Montreal, Montreal, QC, Canada (R Rabasa-Lhoret); Department of Cardiovascular and Diabetes Medicine, University of Dundee, Dundee, UK (R McCrimmon); London Medical, London, UK (C Hume); [A: is there a departmental affiliation for $\mathrm{CH}$ ?] Children and Young People's Diabetes Service, University College London Hospitals NHS Foundation Trust, London, UK 
(F Annan); School of Sport Science, Exercise, and Health (PA Fournier), The University of

Western Australia, Perth, WA, Australia

(ProfT W Jones FRACP); Department of Endocrinology and Diabetes, Princess Margaret Hospital for Children, Perth, WA, Australia (Prof T W Jones); Telethon Kids Institute, Perth, WA, Australia (Prof TW Jones); [TW]: affiliations \& title OK?] Dexcom Inc, San Diego, CA, USA (C Graham); Atlanta Diabetes Associates, Atlanta, GA, USA (B Bode); Department of Pediatrics, University of California Irvine, Irvine, CA, USA (P Galassetti); Department of Physical Medicine and Rehabilitation, University of Colorado, School of Medicine, Aurora, CO, USA (I San Millan); Profil, Neuss, Germany (T Heise); Keck School of Medicine, University of Southern California, Los Angeles, CA, USA (A Peters); StubbaekSkole, Aabenraa, Denmark (A Petz); Division of Endocrinology, Boston Children's Hospital, Boston, MA, USA (L M Laffel); and Pediatric, Adolescent and Young Adult Section, Joslin Diabetes Center, Boston, MA, USA (L M Laffel) [LML: OK to split into two affiliations?] Correspondence to: Dr Michael C Riddell, Muscle Health Research Centre, York University, Toronto, ON M3J 1P3, Canada mriddell@yorku.ca

with prediabetes or type 2 diabetes..$^{18}$ In some studies, high intensity interval training has been shown to be 40 more effective than continuous aerobic training in improvement of cardiovascular fitness and various parameters related to glucose metabolism, including insulin sensitivity and glycaemic control in type 2 diabetes. ${ }^{19}$ At present, it is unclear what the most effective 45 forms of exercise for improvement of cardiometabolic control in type 1 diabetes are..$^{20}$

\section{Neuroendocrine and metabolic responses to exercise Individuals without diabetes}

The metabolic responses to different forms of exercise are distinct. However, in almost all forms of exercise, regardless of the intensity or duration, blood glucose concentrations are normally held within a tight range (4-6 mmol/L). During aerobic exercise, insulin secretion decreases and glucagon secretion increases in the portal vein to facilitate release of glucose from the liver to match
1 the rate of glucose uptake into the working muscles. ${ }^{21}$ Exercise can increase glucose uptake into muscle by up to 50 times-a phenomenon that occurs independently of insulin signalling- ${ }^{22}$ so the decrease in circulating insulin does not restrict glucose provision to the working body. Although the main determinant of glucose production during aerobic exercise is an increase in glucagon concentrations, neural control of glucose release and other counter-regulatory hormones also have 10 a supportive role. ${ }^{23}$ An extended duration of exercise leads to reduced reliance on muscle glycogen as fuel and increased reliance on lipid oxidation and glucose derived from plasma. ${ }^{24}$ If insulin concentrations do not fall during aerobic exercise [A: for example, during...?], the 15 rise in counter-regulatory hormones is less effective than when they do fall [A:OK?] in the promotion of hepatic glucose production. ${ }^{21}$

When the intensity of exercise increases above $50-60 \%$ of maximal oxygen consumption $\left(\mathrm{VO}_{2} \mathrm{max}\right)$, fat oxidation decreases, particularly in those who are untrained, and carbohydrates become the preferred fuel. ${ }^{25}$ Prolonged high intensity exercise is supported by use of both muscle glycogen and blood glucose, with minimal contributions from lipid and protein. ${ }^{26}$ During predominantly anaerobic activities ${ }^{27}$ and during a high intensity interval training session, ${ }^{28}$ circulating insulin concentrations do not decrease as markedly as in purely aerobic activities, in part because the duration of activity is typically shorter. High rates of external power output during high intensity 30 interval training increase reliance on muscle phosphagens and glycogen, with lactate concentrations rising markedly in the circulation. ${ }^{28}$ Insulin concentrations increase above baseline concentrations in early recovery from a high intensity interval training session to offset the rise in glucose caused by the elevations in counter-regulatory hormones and other metabolites. ${ }^{27}$

Dysglycaemia during exercise in individuals with type 1 diabetes In type 1 diabetes, the glycaemic responses to exercise 0 are influenced by the location of insulin delivery, the amount of insulin in the circulation, the blood glucose concentration before exercise, the composition of the last meal or snack, as well as the intensity and duration of the activity $^{29}$ (figure 1).

During aerobic exercise, blood glucose concentrations fall [A: only drop? Or develop hypoglycaemia?] in most individuals with type 1 diabetes, unless they ingest carbohydrates, because insulin concentrations cannot be decreased rapidly enough at the start of the activity and 50 might rise in the systemic circulation, ${ }^{30}$ perhaps because of increased blood flow to subcutaneous adipose tissue during exercise. ${ }^{31}$ Even if basal insulin infusion rates are halved $60 \mathrm{~min}$ before the start of exercise in patients on continuous subcutaneous insulin infusion, circulating free insulin concentrations do not decrease upon commencement of exercise and concentrations tend to increase transiently during the activity. ${ }^{32}$ Increased 
insulin concentrations in the circulation during exercise promote increased glucose disposal relative to hepatic glucose production, and might delay lipolysis-another feature that increases the reliance of muscles on glucose as a fuel. Hypoglycaemia develops in most patients [A: do references refer to children and adolescents only? If so, the term 'patients' may be too general] within about $45 \mathrm{~min}$ of starting aerobic exercise [A: OK as edited?]. ${ }^{33,34}$ Trained individuals with type 1 diabetes have greater reductions in blood glucose concentrations during 10 aerobic exercise than do individuals with reduced physical fitness, ${ }^{35}$ possibly because the overall work rate is higher in those who are more aerobically conditioned than those who are not. As such, both trained and untrained individuals with type 1 diabetes typically 15 require an increased carbohydrate intake [A: before commencing aerobic exercise?] or an insulin dose reduction, or both, [A: OK? Our style is to avoid the "and/ or" contraction, and to replace with "and" or "or"] for prolonged aerobic exercise. High intensity interval sprint 20 training promotes the increased oxidative capacity of skeletal muscle in type 1 diabetes and attenuates the rates of glycogen breakdown ${ }^{36}$ which might, in theory, protect against hypoglycaemia after exercise. Perhaps in line with this, individuals who are aerobically conditioned 25 a have lower glucose variability than do those who are unconditioned. ${ }^{37}$ Low insulin concentrations due to aggressive reductions in insulin administration or a skipped insulin dose can cause hyperglycaemia before and during aerobic exercise, ${ }^{38}$ and even mild activity 30 could lead to development of ketosis. ${ }^{39}$

Resistance exercise is associated with better glucose stability than continuous moderate intensity aerobic exercise, ${ }^{40}$ although resistance exercise could cause a modest rise in glycaemia [A: addition OK?] in some 35 individuals. ${ }^{41}$ Compared with aerobic exercise, a high intensity interval training session attenuates the decrease in glycaemia, ${ }^{42}$ as does resistance exercise done before aerobic exercise, ${ }^{43}$ possibly because of increased concentrations of counter-regulatory hormones and various metabolites that restrict glucose disposal. ${ }^{44}$ In situations of brief and intense anaerobic exercise (eg, sprinting, weight lifting, and some competitive sports), ${ }^{41,45}$ or during high intensity interval training, ${ }^{28}$ glucose concentrations typically rise.

Dysglycaemia after exercise in individuals with type 1 diabetes Glucose uptake into muscle decreases immediately after aerobic exercise, but overall glucose disposal remains elevated for several hours in recovery from exercise to 5 help replenish glycogen stores. ${ }^{46}$ The risk of hypoglycaemia is elevated for at least $24 \mathrm{~h}$ in recovery from exercise, with the greatest risk of nocturnal hypoglycaemia occurring after afternoon activity. ${ }^{47}$ As mentioned above, weight lifting, sprinting, and intense aerobic exercise can promote increase in glycaemia that could last for hours in recovery. Although a conservative

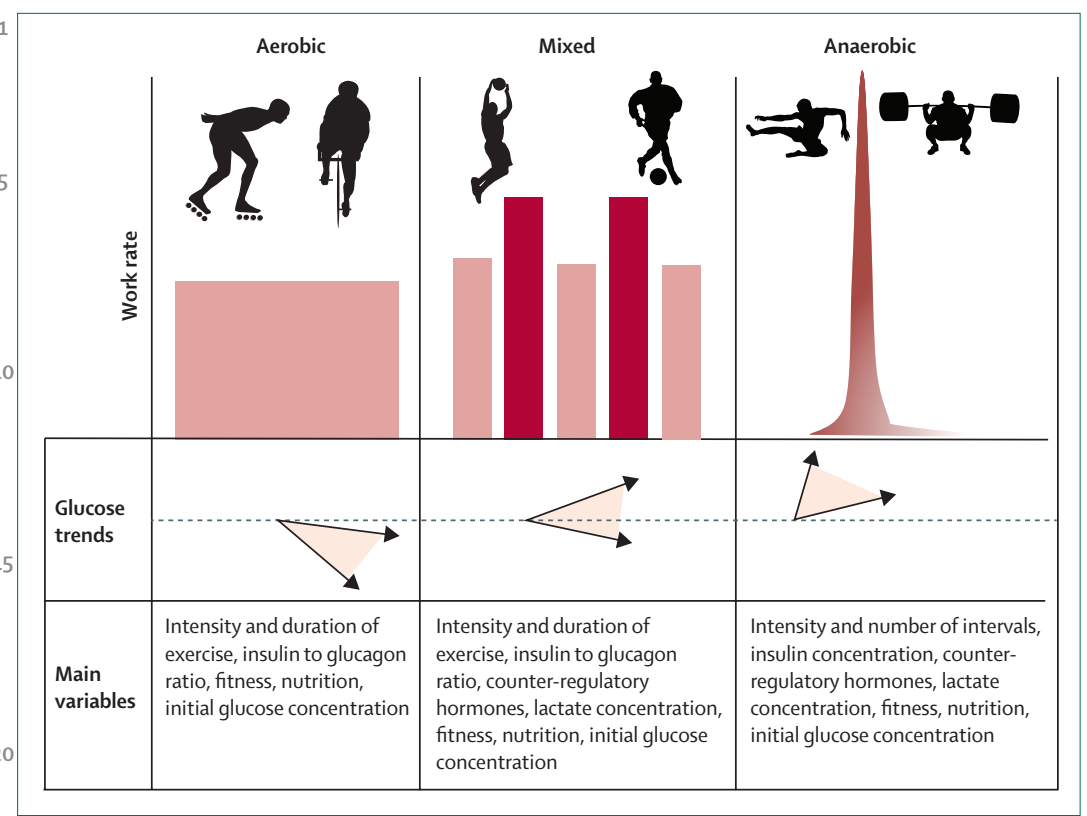

Figure 1: Variability in blood glucose responses to different forms of exercise [A: in people with type 1 diabetes?] High individual variability exists in the blood glucose responses to different form of exercise, as denoted by the arrows and grey shading. In general, aerobic exercise decreases glycaemia, anaerobic exercise increases glycaemia and mixed activities are associated with glucose stability. Individual responses are dependent on various additional factors, including the duration and intensity of the activity, initial blood glucose concentrations, individual fitness, concentrations of insulin, glucagon, and other counter-regulatory hormones in the circulation, and the nutritional status of the individual.

insulin correction after exercise might be prudent in some situations ${ }^{48}$ over-correction with insulin can cause severe nocturnal hypoglycaemia and lead to death. ${ }^{49}$ High intensity interval training has been associated with a higher risk of nocturnal hypoglycaemia than continuous aerobic exercise in some $\mathrm{e}^{50}$-but not all ${ }^{51,52}$ studies.

\section{Exercise goals and glycaemic targets}

Individuals with type 1 diabetes should engage in exercise for various health reasons. The evidence on whether regular exercise improves metabolic control in adults with type 1 diabetes is somewhat scarce, ${ }^{20,53}$ although exercise appears to be helpful in young people with type 1 diabetes.? Exercise readiness questionnaires, such as Physical Activity Readiness Medical Examination (ePARmed-X+) and Physical Activity Readiness ${ }_{5}$ Questionnaire for Everyone (PAR-Q+), are available online for adults with diabetes who might be at increased risk of developing adverse events. Patient goals for exercise (eg, metabolic control, prevention of complications, fitness, weight loss, or competition and performance) should be considered before decisions on diabetes management are made. This is an important element of the diabetes management plan. For example, exercise for weight loss requires strategies that focus on reduction of insulin concentrations during and after exercise, as opposed to consumption of additional carbohydrates. By contrast, if maximisation of sports and exercise performance is the primary goal, then nutritional
For more on ePARmed-X+ and PAR-Q+ see http://eparmedx.com 
Panel 1: Blood glucose concentrations before exercise commencement and recommended glucose management strategies

The carbohydrate intakes shown here aim to stabilise glycaemia at the start of exercise. Blood glucose at the start of exercise must also be viewed within a wider context. Factors to consider include directional trends in glucose and insulin concentrations, patient safety, and individual patient preferences based on experience. Carbohydrate intake will need to be higher if circulating insulin concentrations are high at the onset of exercise.

Starting glycaemia below target $(<5 \mathrm{mmol} / \mathrm{L})$

- Ingest 10-20 g of glucose before starting exercise

- Delay exercise until blood glucose is more than $5 \mathrm{mmol} / \mathrm{L}(90 \mathrm{mg} / \mathrm{dL})$ and monitor closely for hypoglycaemia

Starting glycaemia near target (5-6.9 $\mathrm{mmol} / \mathrm{L})$

- Ingest $10 \mathrm{~g}$ of glucose before starting aerobic exercise

- Anaerobic exercise and high intensity interval training sessions can be started

Starting glycaemia at target levels $(7-10 \mathrm{mmol} / \mathrm{L})$

- Aerobic exercise can be started

- Anaerobic exercise and high intensity interval training sessions can be started but glucose concentrations could increase

Starting glycaemia slightly above target (10.1-15.0 mmol/L)

- Aerobic exercise can be started

- Anaerobic exercise can be started but glucose concentrations could rise

Starting glycaemia above target ( $>15 \mathrm{mmol} / \mathrm{L}$ )

- If the hyperglycaemia is unexplained (not associated with a recent meal), check blood ketones. If ketones are modestly elevated (up to $1.4 \mathrm{mmol} / \mathrm{L}$ ), exercise should be restricted to a light intensity for only a brief duration ( $<30 \mathrm{~min}$ ) and a small corrective insulin dose might be needed before starting exercise. If blood ketones are elevated ( $\geq 1.5 \mathrm{mmol} / \mathrm{L}$ ), exercise is contraindicated and glucose management should be initiated rapidly as per the advice of the health-care professional team.

- Mild to moderate aerobic exercise can be started if blood ketones are low $(<0.6 \mathrm{mmol} / \mathrm{L})$ or the urine ketone dipstick [A: correct?] is less than [A: what is this the equivalent of in $\mathrm{mmol} / \mathrm{L}$ ?] 2+. Blood glucose concentrations should be monitored during exercise to help detect whether glucose concentrations increase further. Intense exercise should be initiated only with caution as it could promote further hyperglycaemia

guidance specific to the sporting activity is needed and a modified insulin plan to match the increased nutritional requirements should be considered. ${ }^{54}$ For all patients, blood glucose monitoring before, during, and after exercise is essential to inform strategies and maintain stable and safe glycaemia.

The appropriate blood glucose concentration at the 4 start of exercise should be tailored to the individual. Based on consensus [A: whose consensus-the authors'?], a reasonable starting range for most patients doing aerobic exercise lasting up to an hour is 7-10 $\mathrm{mmol} / \mathrm{L}$. This range balances performance 5 considerations against the risk of hypoglycaemia. Concentrations higher than 7-10 $\mathrm{mmol} / \mathrm{L}$ might be acceptable in some situations where added protection against hypoglycaemia is needed. Achieving and maintaining circulating glucose concentrations in this range is challenging. The glycaemic response to exercise is variable and based on several factors, including the
1 duration and intensity of exercise, ${ }^{44,55}$ the starting level of glycaemia, ${ }^{34}$ the individual's aerobic fitness, ${ }^{35}$ and the amount of insulin in circulation ${ }^{56,57}$ (figure 1). Anaerobic exercise and a high intensity interval training session can 5 be initiated with a lower starting glucose concentration (5-7 $\mathrm{mmol} / \mathrm{L}$ ) because glucose concentrations tend to remain relatively stable and fall to a lesser extent than with continuous aerobic exercise, or rise slightly (figure 1). Strategies to cope with a range of glucose 10 concentrations before the start of exercise are provided in panel1, bearing in mind that for aerobic activities lasting longer than $30 \mathrm{~min}$, additional carbohydrates are likely to be needed (table 1). If glucose concentrations are too high because of insulin omission, ketosis and further 15 hyperglycaemia can occur, ${ }^{39}$ and work effort [A: please clarify what is meant by "work effort"] probably increases. Although it is unclear if there is an optimal glycaemic range for exercise performance, clinical experience and data from a field study [A: in adolescents?] ${ }^{58}$ suggest that 20 maintenance of a concentration of about $6 \cdot 0-8 \cdot 0$ $\mathrm{mmol} / \mathrm{L}$ might be ideal.

\section{Contraindications and cautions for exercise}

Although few exercise restrictions should be placed on 25 patients, some considerations are important, and are highlighted below.

\section{Elevated ketones}

Hyperglycaemia in conjunction with [A: addition ok?] 30 elevated blood ketones $(\geq 1.5 \mathrm{mmol} / \mathrm{L})$ before a bout of exercise should be addressed before the start of the session via insulin administration or carbohydrate feeding, or both [A: edits OK, to avoid "and/or"?] (panel 1). The cause of elevated ketone concentrations should be 35 identified (illness, diet manipulation, a recent bout of prolonged exercise, insulin omission, etc). Prolonged endurance type activities (eg, marathons and trekking) and diets very low in carbohydrate can elevate blood ketone concentrations in patients. The health-care professional should therefore define appropriate [A: are you referring to blood ketone levels here?] concentrations and provide tailored guidance for each individual. Blood ketone concentrations of $3.0 \mathrm{mmol} / \mathrm{L}$ or more should be managed immediately by a qualified health-care professional (eg, a hospital emergency department or physician).

\section{Recent hypoglycaemia}

Severe hypoglycaemia (defined here as blood glucose $\leq 2.8 \mathrm{mmol} / \mathrm{L}$ or a hypoglycaemic event requiring assistance from another individual) within the previous $24 \mathrm{~h}$ is a contraindication to exercise, because of the substantially increased risk of a more serious episode during exercise. ${ }^{59}$ In situations where minor hypoglycaemia (blood glucose 2.9-3.9 $\mathrm{mmol} / \mathrm{L}$, with the ability to self-treat) has occurred, the increased risk of recurrence must be taken into account. ${ }^{60}$ Vigilance 


\begin{tabular}{|c|c|c|c|}
\hline & $\begin{array}{l}\text { Endurance exercise performance in } \\
\text { athletes with and without diabetes }\end{array}$ & $\begin{array}{l}\text { Hypoglycaemia prevention under low insulin } \\
\text { conditions }\end{array}$ & $\begin{array}{l}\text { Hypoglycaemia prevention under high insulin } \\
\text { conditions }\end{array}$ \\
\hline $\begin{array}{l}\text { Meal (low fat, low glycaemic index) } \\
\text { before exercise }\end{array}$ & $\begin{array}{l}\text { A minimum of } 1 \mathrm{~g} \text { carbohydrate per } \mathrm{kg} \\
\text { body weight according to exercise } \\
\text { intensity and type }\end{array}$ & $\begin{array}{l}\text { A minimum of } 1 \mathrm{~g} \text { carbohydrate per } \mathrm{kg} \text { body weight } \\
\text { according to exercise intensity and type }\end{array}$ & $\begin{array}{l}\text { A minimum of } 1 \mathrm{~g} \text { carbohydrate per } \mathrm{kg} \text { body } \\
\text { weight according to exercise intensity and type }\end{array}$ \\
\hline $\begin{array}{l}\text { Meal immediately [A: is this different } \\
\text { from the low fat low GI meal } \\
\text { timing?] before exercise } \\
\text { (high glycaemic index) }\end{array}$ & $\begin{array}{l}\text { No carbohydrate required for } \\
\text { performance }\end{array}$ & $\begin{array}{l}\text { If blood glucose concentration is less than } 5 \mathrm{mmol} / \mathrm{L} \text {, } \\
\text { ingest } 10-20 \mathrm{~g} \text { carbohydrate }\end{array}$ & $\begin{array}{l}\text { If blood glucose concentration is less than } \\
5 \mathrm{mmol} / \mathrm{L} \text {, ingest } 20-30 \mathrm{~g} \text { carbohydrate }\end{array}$ \\
\hline Meal after exercise & 1-1.2 g carbohydrate per $\mathrm{kg}$ body weight & $\begin{array}{l}\text { Follow sports nutrition guidelines to maximise recovery } \\
\text { with appropriate insulin adjustment for glycaemic } \\
\text { management }\end{array}$ & $\begin{array}{l}\text { Follow sports nutrition guidelines to maximise } \\
\text { recovery with appropriate insulin adjustment for } \\
\text { glycaemic management }\end{array}$ \\
\hline Exercise (up to 30 min duration) & $\begin{array}{l}\text { No carbohydrate required for } \\
\text { performance }\end{array}$ & $\begin{array}{l}\text { If blood glucose concentration is less than } 5 \mathrm{mmol} / \mathrm{L} \text {, } \\
\text { ingest } 10-20 \mathrm{~g} \text { carbohydrate }\end{array}$ & $\begin{array}{l}\text { Might require } 15-30 \mathrm{~g} \text { carbohydrate to prevent } \\
\text { or treat hypoglycaemia }\end{array}$ \\
\hline Exercise (30-60 min duration) & $\begin{array}{l}\text { Small amounts of carbohydrate } \\
(10-15 \mathrm{~g} / \mathrm{h}) \text { could enhance performance }\end{array}$ & $\begin{array}{l}\text { Low to moderate intensity exercise (aerobic): small } \\
\text { amounts of carbohydrate ( } 10-15 \mathrm{~g} / \mathrm{h} \text { ) depending on } \\
\text { exercise intensity and blood glucose concentration } \\
\text { High intensity exercise (anaerobic): no carbohydrate } \\
\text { required during exercise unless blood glucose } \\
\text { concentration is less than } 5 \mathrm{mmol} / \mathrm{L} \text {; if so, ingest } \\
10-20 \mathrm{~g} \text { carbohydrate; replace carbohydrate needs after } \\
\text { exercise }\end{array}$ & $\begin{array}{l}\text { Might require up to } 15-30 \mathrm{~g} \text { carbohydrate every } \\
30 \mathrm{~min}[\mathrm{~A}: \mathrm{OK} \text { ?] to prevent hypoglycaemiav }\end{array}$ \\
\hline Exercise (60-150 min duration) & $30-60 \mathrm{~g}$ carbohydrate per $\mathrm{h}$ & $\begin{array}{l}30-60 \mathrm{~g} \text { carbohydrate per } \mathrm{h} \text { to prevent hypoglycaemia } \\
\text { and enhance performance }\end{array}$ & $\begin{array}{l}\text { Up to } 75 \mathrm{~g} \text { carbohydrate per } \mathrm{h} \text { to prevent } \\
\text { hypoglycaemia and enhance performance* }\end{array}$ \\
\hline $\begin{array}{l}\text { Exercise (>150 min duration); } \\
\text { mixture of carbohydrate sources }\end{array}$ & $\begin{array}{l}\text { 60-90 g carbohydrate per h spread across } \\
\text { the activity (e.g. } 20-30 \mathrm{~g} \text { carbohydrate } \\
\text { every } 20 \mathrm{~min} \text { ) [A:OK?] } \\
\text { Use carbohydrate sources that use } \\
\text { different gut transporters } \\
\text { (eg, glucose and fructose) }\end{array}$ & $\begin{array}{l}\text { Follow sports nutrition guidelines }(60-90 \mathrm{~g} / \mathrm{h}) \\
\text { with appropriate insulin adjustment for glycaemic } \\
\text { management }\end{array}$ & $\begin{array}{l}\text { Follow sports nutrition guidelines }(60-90 \mathrm{~g} / \mathrm{h}) \\
\text { with appropriate insulin adjustment for } \\
\text { glycaemic management }\end{array}$ \\
\hline \multicolumn{4}{|c|}{$\begin{array}{l}\text { These guidelines are based on published studies, }{ }^{6,111,112} \text { and on our own expert opinion. [A: OK - referring to your own (authors') opinions or to expert opinions of other authors? Pls clarify] } \\
{ }^{*} \text { Carbohydrate consumption at a high rate might cause gastric upset in some individuals and might contribute to hyperglycaemia during and after the activity. To increase the rate of carbohydrate absorption } \\
\text { during exercise, and maintain hydration status, sports beverages containing glucose and fructose might be preferable. [A: what do the colours represent?] }\end{array}$} \\
\hline
\end{tabular}

around monitoring should be stressed and exercise should be avoided if the setting is deemed particularly unsafe (eg, swimming or trekking alone).

\section{Diabetes-related complications}

Overall, the health benefits of being physically active outweigh the risks of being sedentary for people with diabetes. Those with complications can derive several 40 health benefits from low intensity physical activities, with little risk of any adverse events. ${ }^{61}$ In individuals with long-standing disease or with $\mathrm{HbA}_{1 \mathrm{c}}$ concentrations well above the target, vigorous exercise, activities involving lifting of heavy weights, and competitive endurance events are contraindicated, particularly if the patient has unstable proliferative retinopathy, severe autonomic dysfunction, or renal failure. ${ }^{61}$

\section{Inadequate preparation for exercise-associated hypoglycaemia}

In preparation for exercise, individuals with type 1 diabetes should be aware of their starting glucose concentrations, and should also have blood glucose monitoring equipment and snacks to treat hypoglycaemia. They should also be advised to wear or carry some form of diabetes identification.

\section{Nutritional management Goals for nutritional management}

35 Nutritional management for people with type 1 diabetes should incorporate strategies that optimise glycaemic control while promoting long-term health. ${ }^{62}$ The main strategies around nutrition for exercise and sport discussed in this section primarily aim to maximise athletic performance and are based largely on studies done in highly trained healthy individuals without diabetes, ${ }^{63}$ with few studies done in people with type 1 diabetes. Application of these strategies to people with type 1 diabetes must consider the individual's insulin management plan and include specific advice focused on nutrition for both athletic performance and glycaemic management. A registered dietitian with specialist diabetes and sports knowledge is the most qualified to help active people with type 1 diabetes.

50 An individualised meal planning approach is central to improvement of performance and glycaemic outcomes. Daily carbohydrate intake should relate to the fuel cost of training in the athletic subpopulation and ensure prevention of hypoglycaemia for all active people. Balancing insulin dose to carbohydrate intake during exercise is essential. Various carbohydrate and insulin adjustment strategies can be used, such as reduction of 
the pre-exercise bolus insulin dose by $30-50 \%$ up to 90 min before aerobic exercise, ${ }^{64}$ consumption of carbohydrates with a high glycaemic index during sport (30-60 g/h), or replacement of carbohydrates after anaerobic exercise. Personal tolerance of ingested carbohydrate, particularly during exercise, is a key factor in tailoring of recommendations. The distribution of macronutrient intake over the day should take into account the timing of exercise so that liver and muscle glycogen stores are maximised before the activity and 1 replenished in early recovery. ${ }^{63}$ This strategy should include carbohydrate feeding well before exercise $(\sim 4 \mathrm{~h})$ and early in recovery. ${ }^{63,65}$

\section{Daily energy and macronutrient balance}

Athletes with type 1 diabetes need sufficient energy to meet the demands of their daily activities. These demands will vary with age, sex, body composition, and activity type. ${ }^{66}$ Total energy requirements differ with individual aims. Predictive equations can be used to estimate resting energy expenditure, ${ }^{67}$ however, they should serve only as a guide, as they could overestimate or underestimate actual requirements. An appropriate macronutrient balance and micronutrient intake, ${ }^{63}$ coupled with a glycaemic control strategy, is required to maximise performance. The optimal macronutrient distribution will vary depending on the individualised assessment and exercise goals. A guide to the nutritional distribution of the total daily energy intake is as follows: 45-65\% carbohydrate, $20-35 \%$ fat, and $10-35 \%$ protein, 30 with higher protein intakes indicated for individuals wanting to lose weight. ${ }^{6}$

The major nutrients required to fuel performance are carbohydrates and lipids, while the addition of protein is needed to help foster recovery and maintain nitrogen balance. ${ }^{63,69}$ Protein requirements range from $1 \cdot 2$ to $1.6 \mathrm{~g}$ per kg body weight per day, and will vary with training type and intensity, and carbohydrate availability. ${ }^{63,70}$ Higher intakes might be needed for recovery from injury or for individuals on energy-restricted $\operatorname{diets}^{71}$ to maintain 40 lean body mass.

Carbohydrate needs before, during, and after exercise A distinction should be made between carbohydrate needs for performance and carbohydrate intake required 4 for hypoglycaemia prevention (table 1). [A: the first time a table, panel, or figure is mentioned in the text, any references in the table or figure that have not already been mentioned in the text should go into the reference list at that point, not at the end; refs 111 and 112 will therefore be moved here and cited after ref 71] Carbohydrate requirements will alter insulin management strategies and vice versa. Most studies in type 1 diabetes have investigated the amount and distribution of carbohydrate required to prevent 5 hypoglycaemia rather than to optimise performance, although the two might be at least partially related. ${ }^{34,64,72,73}$
For example, although only $15-20 \mathrm{~g} / \mathrm{h}$ of carbohydrate might be required to prevent hypoglycaemia in people who reduce their insulin concentrations in anticipation of exercise, this amount of carbohydrate could be insufficient for performance. Implementation of increased carbohydrate supplementation (up to $75 \mathrm{~g} / \mathrm{h}$ ) is possible for prolonged activity lasting longer than 2.5 hours (eg, marathons and other endurance type races) without having an adverse effect on glycaemia, as long as the insulin dose is titrated appropriately. ${ }^{54}$ In general, carbohydrate requirements during shorter, intermittent, high-intensity, and anaerobic activities can be considerably decreased (table 1).

\section{Nutritional needs for recovery}

Nutrition requirements to maximise muscle recovery and muscle protein synthesis after exercise have been well studied in the athletic population without diabetes. ${ }^{74}$ For replenishment of glycogen content after exercise, carbohydrate intake is essential. ${ }^{63}$ For athletes with type 1 diabetes, rapid and adequate replenishment of muscle and liver glycogen stores is essential to help prevent late onset hypoglycaemia. Glycogen replacement strategies could also be important in prevention of euglycaemic ketosis in exercise recovery. ${ }^{75}$ Ingestion of protein $(\sim 20-30 \mathrm{~g})$ in addition to carbohydrate in the period after exercise is beneficial for muscle protein synthesis, but protein ingestion does not appear to facilitate glycogen replenishment in athletes who do not have diabetes. ${ }^{63}$

\section{Role of high and low glycaemic index foods for maintenance of euglycaemia}

The glycaemic index of a carbohydrate-rich food can be used to assist with the selection of the carbohydrate type for exercise; sports drinks and energy gels with a high glycaemic index provide rapidly released carbohydrate to increase blood glucose concentrations during endurance events and can [A: ok?] treat hypoglycaemia. Consumption of foods with a low glycaemic index before exercise could sustain carbohydrate availability and maintain euglycaemia, whereas consumption of meals and snacks with a high glycaemic index after exercise could enhance recovery. Snacks with a low or moderate glycaemic index could also be preferred for long-distance activities such as trekking and long-distance cycling at low to moderate workloads. Consumption of a carbohydrate with a low glycaemic index (isomaltose) 2 hours before a high intensity run in... [A: please describe study population] showed better blood glucose responses during exercise than did consumption 50 of a carbohydrate with a high glycaemic index (dextrose). ${ }^{76}$ Consumption of a meal and bedtime snack with a low glycaemic index [A: snack also low GI?] after evening exercise in...[A: please describe study population] prevented postprandial hyperglycaemia more effectively than [A: edit correct?] a meal and snack with a high glycaemic index [A: snack also high GI?], with both meal types being protective against hypoglycaemia for about $8 \mathrm{~h} .^{77}$ The 
protection provided by a snack was not sustained beyond $8 \mathrm{~h}$, and the risk of hypoglycaemia remained high [A: for how long?]."

\section{Fluid replacement}

Adequate fluid intake before, during, and after exercise is necessary for prevention of dehydration and optimisation of performance. ${ }^{65}$ Water is the most effective drink for low-intensity and short-duration sports (ie, $\leq 45 \mathrm{~min}$ ), as long as glucose concentrations are $7 \mathrm{mmol} / \mathrm{L}$ or higher. Sports beverages containing carbohydrate (6-8\%) and electrolytes are useful for athletes with type 1 diabetes exercising for a longer duration; they are also useful as a hydration and fuel source for higher intensity exercise, and for prevention of hypoglycaemia. ${ }^{34,78}$ However, overconsumption of these beverages can result in hyperglycaemia. Milkbased drinks containing carbohydrate and protein can assist with recovery after exercise [A: correct?] and prevent delayed hypoglycaemia. ${ }^{73}$

\section{Low-carbohydrate high-fat diets and exercise}

People with type 1 diabetes can choose a low carbohydrate high fat diet for various reasons. A review on low carbohydrate high fat diets and sports performance in 25 individuals without type 1 diabetes concluded that, despite increasing the ability of muscles to utilise fat over time, no evidence was available to suggest performance benefits. ${ }^{79}$ Long-term studies have yet to be done on the health, glycaemia, or performance effects of low carbohydrate high fat diets in people with type 1 diabetes. A concern with these diets is that they could impair the capacity for high-intensity exercise. ${ }^{80}$

5 Variation in carbohydrate intake (ie, periodisation throughout the training cycle according to fuel needs and performance) has been suggested by some researchers as a way to help promote adaptation of skeletal muscle to training. ${ }^{81}$ Additionally, various exercise-nutrient protocols are used to manipulate carbohydrate availability, such as training in a fasting state or withholding carbohydrate intake at a meal before or after exercise. These approaches have not been studied in individuals with type 1 diabetes, in whom manipulation of dietary carbohydrate as part of training presents unique challenges for insulin therapy and requires careful glucose monitoring.

\section{Sports nutritional aids and type 1 diabetes}

20 The use of ergogenic aids is a widespread performance enhancement strategy used by athletes, but little evidence is available on their use in athletes with type 1 diabetes.

Caffeine intake in athletes without diabetes has shown improvements in endurance capacity and power output. ${ }^{82}$ Caffeine intake (5-6 mg per $\mathrm{kg}$ body mass) before exercise attenuates decrease in glycaemia during exercise in individuals with type 1 diabetes, but it might increase the risk of late onset hypoglycaemia. ${ }^{83}$

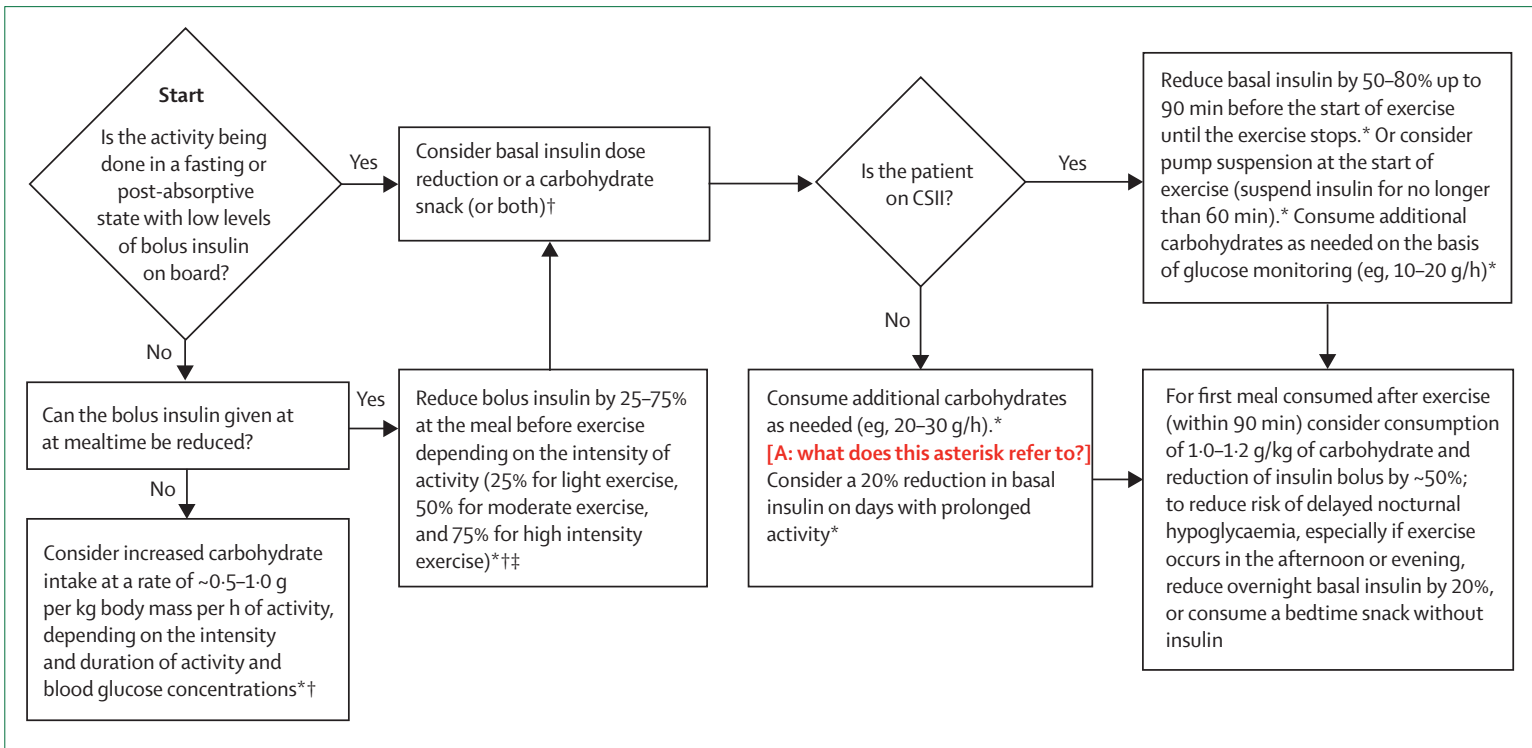

Figure 2: Decision tree for aerobic exercise and mixed aerobic and anaerobic activities lasting 30 min or longer in people with type 1 diabetes [A: correct?] This decision tree can serve as a starting point for individuals with type 1 diabetes [A: correct?] planning to do aerobic exercise. *Mixed activities that include anaerobic bursts of exercise might require a lower carbohydrate intake or lower [A:OK?] insulin dose reductions than continuous moderate aerobic activities. †If both resistance and aerobic exercise are to be done, resistance exercise could be done first to help attenuate hypoglycaemia. ‡In some situations, such as... [A: please complete], increased carbohydrate feeding rather than insulin dose reduction might help improve endurance performance in prolonged activities. In other situations, both bolus and basal insulin dose reductions might be needed to help restrict or reduce carbohydrate intake. [A: OK as edited?] Continuous glucose monitoring could be considered where patient or parent preference dictates, or in individuals with a history of nocturnal or severe hypoglycaemia. CSII=continuous subcutaneous insulin infusion. [A: what does the red asterisk correspond to?] 
Panel 2: Factors that to consider before adjustments are made for exercise in individuals with type 1 diabetes

Subcutaneous insulin injection and its adjustments

- Differences in the site and depth of insulin injection affect absorption characteristics ${ }^{13,114}$

- Lipodystrophy can lead to... [A: please complete]

- Inadequate understanding [A:OK?] of insulin pharmacokinetics often leads to inappropriate insulin adjustments, including excessive insulin corrections (stacking), which could be particularly dangerous after exercise

- Rapid acting, ${ }^{30}$ regular, and intermediate acting, ${ }^{115,116}$ but probably not long acting, ${ }_{1}^{117}$ insulin absorption rates are increased with exercise

Carbohydrate intake

- Variation in carbohydrate quantity (including inaccuracy in measurement of intake) and type will affect glycaemic excursions ${ }^{118}$

Self-monitoring of capillary blood glucose and continuous glucose monitoring

- Errors in self-monitored blood glucose sampling or measurement errors during self-monitoring or continuous glucose monitoring could result in inappropriate insulin dose estimations ${ }^{119,120}$

- Although the accuracy of continuous glucose monitoring is improving, it can be compromised by poor accuracy in self-monitoring and calibrations methods ${ }^{121}$

- The lag time in continuous glucose monitoring could affect accuracy during exercise $\mathrm{e}^{104,106}$

Medications and alcohol

- Insulin sensitivity might be affected ${ }^{99}$ as might glucose monitoring tool ${ }^{120}$

Physiological cycles

- Diurnal endocrine variation, the menstrual cycle, and pregnancy affect insulin sensitivity and glycaemic pattern $\mathbf{s}^{122}$

Changes in work and sleep patterns

- Such changes require adjustments in timing of basal insulin dose administration

- The timing of exercise should be considered relative to insulin sensitivity and the risk of nocturnal hypoglycaemia ${ }^{47}$

Intercurrent illness and stress

- Intercurrent illness or stress might necessitate changes in both basal and bolus insulin dose $^{123}$

- Vigorous exercise is contraindicated
1 By contrast, brief anaerobic exercise (eg, sprinting or weight lifting) could require increased insulin delivery, which is typically given in early recovery rather than before exercise for obvious safety reasons. ${ }^{48}$ Strategies for 5 insulin dose adjustments and [A: "and" OK?] carbohydrate intake during and after planned exercise are presented in table 2 and table 3. [A: citation to table 3 (previously table 5) added here so that first mention of table 3 is not within a non-text item. Refs 113-123 (in panel 2) and ref 124 (in 10 table 2) will be cited after ref 83.$]$

\section{Insulin adjustment for prolonged activities: bolus insulin approaches}

Reductions in the bolus insulin dose accompanying [A: $15 \mathrm{ok}$ ?] the meal before exercise and [A: "and" OK?] consumption of additional carbohydrate during exercise are typically needed to avoid hypoglycaemia during prolonged exercise (>30 min)..$^{34,55,64,84-86}$ Bolus dose reductions require planning in advance and are probably only 20 appropriate for exercise with a predictable intensity performed within 2-3 h after a meal. As shown in table 3, the extent of a mealtime dose reduction is proportional to both the intensity and duration of the physical activity. This approach is safe and effective; even reducing the bolus 25 insulin dose by as much as $75 \%$ does not appear to increase ketone production during exercise. ${ }^{86}$

Another strategy is to combine a $75 \%$ reduction of the bolus insulin dose before exercise with ingestion of a snack or meal with a low glycaemic index.$^{87}$ This method 30 also reduces the risk of hyperglycaemia before exercise. However, this approach will not protect against hypoglycaemia if the exercise is performed an hour or more after consumption of the snack. ${ }^{87}$ As such, this combined approach might be preferable only for early [A: 35 are you referring to time of day? Or exercise soon after a meal?] postprandial exercise.

\section{Basal insulin approaches}

Late postprandial hypoglycaemia ( $>4 \mathrm{~h}$ after a meal) 40 following aerobic exercise is driven partly by circulating basal insulin concentrations. Elevated insulin sensitivity after exercise, and possibly a blunting of glucose counter-regulation, appear to place individuals at risk for at least $12 \mathrm{~h}$. Reduction of circulating basal insulin concentrations can ameliorate this risk. For patients on multiple daily insulin injections, clinical observations and limited experimental data ${ }^{88}$ show that reduction of long-acting basal (as well as prandial) insulin concentrations before exercise reduces the risk of 50 hypoglycaemia during and after the activity, but might promote hyperglycaemia at other points during the day. Therefore, reduction in the basal insulin dose for patients on multiple daily insulin injections should not be routinely recommended but can be a therapeutic option for those engaging in considerably more planned activity than usual (eg, camps or tournaments). In general, basal insulins with a short half-life, such as NPH insulin or 


\begin{tabular}{|c|c|c|}
\hline & Prolonged endurance exercise (predominantly aerobic) & Brief intense exercise (aerobic and anaerobic) \\
\hline $\begin{array}{l}\text { Bolus insulin dose reduction at pre-exercise } \\
\text { meal }\end{array}$ & $\begin{array}{l}\text { Advised when exercise occurs within } \sim 120 \text { min of bolus } \\
\text { dose; the magnitude of reduction varies according to timing, } \\
\text { type, duration, and intensity of exercise }\end{array}$ & $\begin{array}{l}\text { Bolus reduction not advised; might require } \\
\text { additional conservative bolus dose correction if } \\
\text { hyperglycaemia develops }\end{array}$ \\
\hline $\begin{array}{l}\text { Before exercise, basal insulin dose reduction } \\
\text { (of } 20 \% \text { in patients on multiple daily } \\
\text { injections }\end{array}$ & $\begin{array}{l}\text { Useful especially if exercise is done less than every } 3 \text { days or if } \\
\text { the frequency of exercise is high throughout the day; might } \\
\text { also be useful if patients are on twice daily intermediate insulin }\end{array}$ & Basal insulin dose reduction not advised \\
\hline $\begin{array}{l}\text { Basal nocturnal insulin dose reduction (of } \\
20 \% \text { ) after exercise in patients on multiple } \\
\text { daily injections and continuous subcutaneous } \\
\text { insulin infusion to reduce the risk of } \\
\text { nocturnal hypoglycaemia }\end{array}$ & $\begin{array}{l}\text { Particularly important if the exercise was done in the } \\
\text { afternoon or early evening }\end{array}$ & $\begin{array}{l}\text { Useful for helping to prevent hypoglycaemia } \\
\text { after a high intensity interval training exercise } \\
\text { session }\end{array}$ \\
\hline $\begin{array}{l}\text { Temporary basal rate change } \\
\text { (continuous subcutaneous insulin infusion) }\end{array}$ & $\begin{array}{l}\text { Basal rate should be reduced to as low as total suspension of } \\
\text { normal basal rate [A: please clarify] during exercise; to take } \\
\text { into account rapid acting insulin pharmacokinetics, this } \\
\text { basal rate reduction should ideally occur well before exercise } \\
\text { is started (up to } 90 \text { min); normal basal rates can be resumed } \\
\text { either at the end of exercise, or later in recovery depending } \\
\text { on glucose trends }\end{array}$ & $\begin{array}{l}\text { Increased basal rate might be needed to help } \\
\text { prevent or treat hyperglycaemia either during } \\
\text { or immediately after exercise }\end{array}$ \\
\hline Carbohydrate intake before exercise & See table 1 for details & Not usually needed \\
\hline Carbohydrate intake during exercise & $\begin{array}{l}\text { Typically up to } 60 \mathrm{~g} / \mathrm{h} \text { if no insulin dose adjustments have } \\
\text { been made (see table } 1 \text { for additional information) }\end{array}$ & Not usually needed \\
\hline Carbohydrate intake after exercise & $\begin{array}{l}\text { Useful to reduce the risk of hypoglycaemia and improve } \\
\text { recovery; might need a specified bolus insulin dose } \\
\text { depending on the length and intensity of exercise } \\
\text { (eg, a reduced insulin to carbohydrate ratio) [A:OK?] }\end{array}$ & $\begin{array}{l}\text { Useful to reduce the risk of hypoglycaemia and } \\
\text { enhance recovery but should be delayed if } \\
\text { hyperglycaemia is initially observed; might } \\
\text { need a specified bolus insulin strategy } \\
\text { (eg, a reduced insulin to carbohydrate ratio) }\end{array}$ \\
\hline Sprint before or after exercise & Might help reduce the risk of hypoglycaemia & $\begin{array}{l}\text { Might increase the risk of hyperglycaemia; } \\
\text { consider a prolonged aerobic cool down }\end{array}$ \\
\hline
\end{tabular}

insulin detemir, seem to lead to less hypoglycaemia in 30 conjunction with exercise than do basal insulins with a longer half-life, such as insulin glargine,$^{89}$ although the mechanism through which this occurs is unclear. Although ultra-long-acting insulins (eg, insulin degludec, with a $25 \mathrm{~h}$ half-life) pose similar risks of hypoglycaemia 35 with endurance exercise to those of insulin glargine, ${ }^{90}$ dose reductions for exercise would have to be implemented at least $48 \mathrm{~h}$ before planned exercise. This is not recommended [A: by the consensus authors?], as it would compromise overall [A: glycaemic?] control.

Continuous subcutaneous insulin infusion offers the flexibility to modify basal infusion delivery and obtain a quick effect (within 1-2 h).$^{91}$ Suspension of basal insulin infusion at the onset of $60 \mathrm{~min}$ exercise reduces the risk of hypoglycaemia during the activity, but it could increase the risk of hyperglycaemia after exercise. ${ }^{92}$ Moreover, glucose concentrations could still decrease by $2-3 \mathrm{mmol} / \mathrm{L}$ over 30-60 min even when basal insulin is dramatically reduced (or completely suspended), ${ }^{64,92,93}$ because of the lag time in the change in circulating insulin 5 concentrations. Where practical, a basal rate reduction, rather than suspension, should be attempted 60-90 min before the start of exercise. An $80 \%$ basal reduction at the onset of exercise helps mitigate hyperglycaemia after exercise more effectively [A: correct?] than does basal 55 insulin suspension, and appears to be associated with a reduced risk of hypoglycaemia both during and after the

\begin{tabular}{|c|c|c|}
\hline & \multicolumn{2}{|l|}{ Exercise duration } \\
\hline & $30 \mathrm{~min}$ & $60 \mathrm{~min}$ \\
\hline Mild aerobic exercise $\left(\sim 25 \% \mathrm{VO}_{2} \max \right)$ & $-25 \% *$ & $-50 \%$ \\
\hline Moderate aerobic exercise $\left(\sim 50 \% \mathrm{VO}_{2} \max \right)$ & $-50 \%$ & $-75 \%$ \\
\hline Heavy aerobic exercise $\left(70-75 \% \mathrm{VO}_{2} \max \right)$ & $-75 \%$ & NA \\
\hline Intense aerobic or anaerobic exercise ( $\left.>80 \% \mathrm{VO}_{2} \max \right)$ & No reduction recommended & NA \\
\hline \multicolumn{3}{|c|}{ 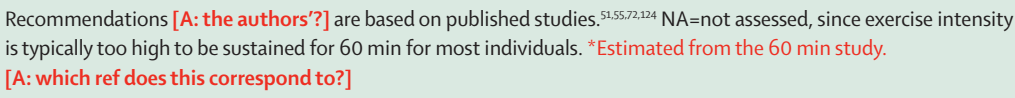 } \\
\hline
\end{tabular}

activity. ${ }^{64}$ However, the optimal timing of basal rate reductions for aerobic and high intensity exercise activities and the maximal safe duration for insulin pump suspension have yet to be determined and remain open to debate. To limit the risk of compromised glycaemic control and ketosis, a time limit of less than $2 \mathrm{~h}$ is proposed [A: by yourselves?] on the basis of rapid-acting insulin pharmacokinetics. ${ }^{91}$

Hyperglycaemia commonly occurs in patients after intense exercise, particularly if insulin concentrations are reduced. Continuous subcutaneous insulin infusion 5 seems to offer advantages over multiple daily insulin injections in the management of early onset ${ }^{94}$ and late onset hypoglycaemia after exercise, ${ }^{95}$ because of the 


\section{Search strategy and selection criteria}

We searched PubMed and other relevant biomedical databases for articles containing the terms "type 1 diabetes" or "insulin-dependent diabetes" and "exercise" or "physical activity", published between January, 1990 and July, 2016, [A: possible to give dates in the format "month, date, year"?] filtered for studies in human beings, and restricted to English language publications. Additional searches were done with the following terms for various subtopics within this Review: "nutrition", "dietary carbohydrate", "dietary protein", "glycaemic index", "hypoglycaemia", "energy expenditure", "glycaemic control", "management", "hypoglycaemia", "hyperglycaemia", or "prevention and control". increased flexibility around basal insulin adjustments. Overcorrection of hyperglycaemia after exercise via repeated insulin dose administration results in an increased risk of severe late onset hypoglycaemia, which 2 could even be fatal. ${ }^{49}$

\section{Strategies to reduce the risk of late onset hypoglycaemia after exercise}

Increased insulin sensitivity lasts up to $24-48 \mathrm{~h}$ following 2 exercise. ${ }^{46}$ Few studies have tested various nutrient or insulin dose adjustments to prevent hypoglycaemia after exercise. Nocturnal hypoglycaemia after exercise commonly occurs in individuals with type 1 diabetes, ${ }^{96}$ with an increased risk after afternoon exercise..$^{47,97}$ Immediate increases in insulin sensitivity after exercise can be addressed through a reduction of about $50 \%$ in the bolus insulin dose administered at meal after exercise, along with consumption of a snack with a low glycaemic index at bedtime. ${ }^{77}$ In one study of 16 young people using an insulin pump, a temporary basal rate reduction of about $20 \%$ at bedtime for $6 \mathrm{~h}$ reduced the risk of nocturnal hypoglycaemia [A: OK as edited?]. ${ }^{95}$ Similarly, in another study of ten men on multiple daily insulin injections, a $20 \%$ basal rate reduction on the day 40 of exercise along with provision of a free carbohydrate snack at bedtime $(0.4 \mathrm{~g}$ carbohydrate per $\mathrm{kg}$ body mass $)$ reduced the risk of nocturnal hypoglycaemia. ${ }^{88}$ Individuals at high risk of severe nocturnal hypoglycaemia (eg, those with recurrent hypoglycaemia and those sleeping alone) should take additional preventive measures, including blood glucose checks at $0200 \mathrm{~h}$ or $0300 \mathrm{~h}$, or the use of a real time continuous glucose monitoring system with alarms and automatic pump suspension. ${ }^{98}$ Consumption of a snack alone, without 50 changing basal insulin therapy, does not appear to entirely eliminate the risk of nocturnal hypoglycaemia, ${ }^{77}$ and alcohol intake might increase the risk. ${ }^{99}$

\section{Emerging tools for exercise management}

Several treatment regimens exist for people with type 1 diabetes. Continuous subcutaneous insulin infusion
1 offers better flexibility in basal insulin adjustments and management of exercise-associated hyperglycaemia than other methods of insulin delivery [A: comparator correct?]. ${ }^{100}$ Continuous subcutaneous insulin infusion is 5 associated with reduced hyperglycaemia after exercise compared with multiple daily insulin injections, ${ }^{94}$ but can create frustrating challenges for sports requiring disconnection of the insulin pump, for example... [A: please complete]. ${ }^{101}$ Continuous subcutaneous insulin 10 infusion could also contribute to a greater sense of being diseased and social stigma in some individuals by drawing undue attention to their condition [A: is there more stigma with CSII than MDI?]. ${ }^{101}$ Prolonged disconnection of the pump (>60 min) should be managed by reconnecting, 15 testing, and re-infusion of the pump if necessary, or by switching to basal insulin provision by needle. Continuous glucose monitoring provides comprehensive information on blood glucose concentrations, real-time trends, and rates of change, which can be used to prevent low 0 concentrations during exercise ${ }^{102}$ even in unique settings where self-monitoring of blood glucose is difficult. ${ }^{103}$ Existing sensors are reasonably accurate for exercise, ${ }^{104,105}$ however, the lag time in glucose equilibrium with the interstitial space and the rapid turnover in glucose during exercise might affect accuracy (ie, overestimate blood glucose when concentrations are dropping and underestimate it when concentrations are rising)..$^{106,107}$

Structured educational sessions can be implemented by downloading data on self-monitoring of blood glucose, o continuous glucose monitoring, and continuous subcutaneous insulin infusion. ${ }^{108}$ Continues glucose monitoring systems now offer the option to add followers who can view glucose concentrations in real time and potentially alert the patient while they are playing sports. Threshold suspension of insulin delivery in continuous subcutaneous insulin infusion could offer additional protection against exercise-associated hypoglycaemia, according to some data. ${ }^{109}$ The development of a fully artificial pancreas for exercise remains an elusive goal. ${ }^{110}$

\section{Conclusion}

Regular physical activity should be a routine objective for patients with type 1 diabetes, for various health and fitness reasons. Considerable challenges remain for people with type 1 diabetes, and their health-care team, in management of exercise and sports. Several small observational studies and a few clinical trials have been published to date that help to inform the consensus recommendations presented here. More studies are needed to determine how to best prevent exerciseassociated hypoglycaemia with basal rate insulin dose adjustments and how to manage glycaemia in the recovery period after exercise. In general, aerobic exercise is associated with reductions in glycaemia, whereas 55 anaerobic exercise might be associated with a transient increase in glucose concentrations. Both forms of exercise can cause delayed-onset hypoglycaemia in 
recovery. A sound understanding of the physiology of 14 different forms of exercise and the variables that can influence glycaemia during exercise and sport should underpin the implementation of safe and effective glycaemic management strategies. For aerobic exercise, 5 reductions in insulin administration before the activity (ie, reductions in basal or bolus insulin, or both) can help ameliorate the risk of hypoglycaemia, as can increasing carbohydrate intake to $60 \mathrm{~g}$ per $\mathrm{h}$ or more. For anaerobic exercise, conservative insulin dose corrections might be 10 required, although this too might increase the risk of nocturnal hypoglycaemia, particularly if the exercise is performed late in the day. In all instances, additional vigilance around glucose monitoring is needed before, during, and after the physical activity.

\section{Contributors}

The literature search was done by MCR, IWG, and CES. All authors (MCR, IWG, CES, CET, PA, ANL, AK, RRL, RM, CH, FA, PAF, CG, BB, PG, TWJ, ISM, TH, APete, APetz, and LML) contributed to the original draft of the manuscript. MCR, FA, and CES edited the revised manuscript. All authors approved the final submission. [A: statement OK?]

\section{Declaration of interests}

MCR has received personal fees from Medtronic Diabetes, Lilly, Ascensia Diabetes Care, and Insulet Corporation. CET has received personal fees from the Juvenile Diabetes Research Foundation (JDRF). PA has received personal fees from Abbott, Dexcom, Lilly, Medtronic, Nordic Infucare, Novo Nordisk, Roche, and Sanofi. He has also been a participant on advisory boards for Abbott, Lilly, and Roche during the course of this work. [A:OK? ANL has received speaking fees from Novo Nordisk, Sanofi, Animas, Eli Lilly, and MSD, and is on the advisory board of Animas. [A:OK?] RR-L has received grants and personal fees from Astra Zeneca, consultancy fees from Boehringer Ingelheim, grants and personal fees from Eli Lilly, grants from Merck, Novo-Nordisk, and Sanofi-Aventis, and personal fees from Medtronic and Takeda. [A:OK?] RM has received personal fees from Novo Nordisk and Sanofi, and is on the advisory boards of both companies. [A:OK?] FA has received registration fees from Novo Nordisk and personal fees from JDRF Peak Program. CG is employed by Dexcom, Inc. BB has received grants and personal fees from Medtronic Diabetes, Novo Nordisk, Sanofi, Janssen, and Lilly, personal fees from Insulet Corporation and Astra 35 Zeneca, and grants from Abbott and DexCom. TH has received grants from Adocia, AstraZeneca, Becton Dickinson, Biocon, Boehringer Ingelheim, Dance Pharmaceuticals, Grünenthal, Gulf Pharmaceuticals, Johnson \& Johnson, Marvel, MedImmune, Medtronic, Novartis, Roche Diagnostics, Sanofi, Senseonics, and Zealand Pharma; grants, personal fees, and non-financial support from Eli Lilly and Novo Nordisk, and personal fees from Mylan. APete has received consulting and speaking fees from Abbott Diabetes Care, Becton Dickinson, Boehringer Ingelheim, Eli Lilly and Company, Janssen, Lexicon, Medscape, Merck, Novo Nordisk, Omada Health, OptumRx, Roche, and Sanofi, research grants from Dexcom, and editorial fees from Medscape. [A:OK?] All other authors declare no competing interests. [A: please ensure this statement matches the information provided on your ICMJE forms. Awaiting disclosure statements from CES, CH, ISM, APetz, and LML.]

\section{Acknowledgments}

This consensus statement was supported, in part, by the Juvenile Diabetes Research Foundation (JDRF) Peak Program. [A:OK?]

\section{References}

$1 \quad$ Mayor S. Insulin pumps improve glucose control in children with type 1 diabetes, study finds. BMJ 2015; 351: h5998.

2 McKnight JA, Wild SH, Lamb MJE, et al. Glycaemic control of Type 1 diabetes in clinical practice early in the 21st century: an international comparison. Diabet Med J Br Diabet Assoc 2015; 32: 1036-50.

3 Bohn B, Herbst A, Pfeifer M, et al. Impact of physical activity on glycemic control and prevalence of cardiovascular risk factors in adults with type 1 diabetes: a cross-sectional multicenter study of 18,028 patients. Diabetes Care 2015; 38: 1536-43.
McCarthy MM, Funk M, Grey M. Cardiovascular health in adults with type 1 diabetes. Prev Med 2016; 91: 138-43.

5 Herbst A, Kordonouri O, Schwab KO, Schmidt F, Holl RW, for the DPV Initiative of the German Working Group for Pediatric

Diabetology Germany. Impact of physical activity on cardiovascular risk factors in children with type 1 diabetes: a multicenter study of 23,251 patients. Diabetes Care 2007; 30: 2098-100.

6 Quirk H, Blake H, Tennyson R, Randell TL, Glazebrook C. Physical activity interventions in children and young people with type 1 diabetes mellitus: a systematic review with meta-analysis. Diabet Med J Br Diabet Assoc 2014; 31: 1163-73.

7 Quirk H, Blake H, Tennyson R, Randell TL, Glazebrook C. Physical activity interventions in children and young people with type 1 diabetes mellitus: a systematic review with meta-analysis. Diabet Med J Br Diabet Assoc 2014 Oct; 31: 1163-73. [A: this is a duplicate of ref 6; will be removed and references renumbered from this point]

8 Katz M, Giani E, Laffel L. Challenges and opportunities in the management of cardiovascular risk factors in youth with type 1 diabetes: lifestyle and beyond. Curr Diab Rep 2015; 15: 119.

15 Kriska AM, LaPorte RE, Patrick SL, Kuller LH, Orchard TJ. The association of physical activity and diabetic complications in individuals with insulin-dependent diabetes mellitus: the Epidemiology of Diabetes Complications Study-VII. J Clin Epidemiol 1991; 44: 1207-14.

10 Chimen M, Kennedy A, Nirantharakumar K, Pang TT, Andrews R, Narendran P. What are the health benefits of physical activity in type 1 diabetes mellitus? A literature review. Diabetologia 2012; 55: 542-51.

11 Pierre-Louis B, Guddati AK, Khyzar Hayat Syed M, et al. Exercise capacity as an independent risk factor for adverse cardiovascular outcomes among nondiabetic and diabetic patients. Arch Med Sci AMS 2014; 10: 25-32.

2512 Brazeau AS, Rabasa-Lhoret R, Strychar I, Mircescu H. Barriers to physical activity among patients with type 1 diabetes. Diabetes Care 2008; 31: 2108-09.

13 Jabbour G, Henderson M, Mathieu ME. Barriers to active lifestyles in children with type 1 diabetes. Can J Diabetes 2016; 40: 170-72.

14 Lascar N, Kennedy A, Hancock B, et al. Attitudes and barriers to 30 exercise in adults with type 1 diabetes (T1DM) and how best to address them: a qualitative study. PLoS One 2014; 9: e108019.

15 Robertson K, Riddell MC, Guinhouya BC, Adolfsson P, Hanas R. Exercise in children and adolescents with diabetes. Pediatr Diabetes 2014; 15 (suppl 20): 203-23.

16 Galler A, Lindau M, Ernert A, Thalemann R, Raile K. Associations between media consumption habits, physical activity, socioeconomic status, and glycemic control in children, adolescents, and young adults with type 1 diabetes. Diabetes Care 2011; 34: 2356-59.

17 Batacan RB, Duncan MJ, Dalbo VJ, Tucker PS, Fenning AS. Effects of high-intensity interval training on cardiometabolic health a systematic review and meta-analysis of intervention studies. Br J Sports Med 2016; published online Oct 20.DOI: 10.1136/ bjsports-2015-095841.

18 Colberg SR, Sigal RJ, Yardley JE, et al. Physical activity/exercise and diabetes: a position statement of the American Diabetes Association. Diabetes Care 2016; 39: 2065-79.

19 Mitranun W, Deerochanawong C, Tanaka H, Suksom D. Continuous vs interval training on glycemic control and macro- and 45 microvascular reactivity in type 2 diabetic patients. Scand J Med Sci Sports 2014; 24: e69-76.

20 Yardley JE, Hay J, Abou-Setta AM, Marks SD, McGavock J. A systematic review and meta-analysis of exercise interventions in adults with type 1 diabetes. Diabetes Res Clin Pract 2014; 106: 393-400.

5021 Camacho RC, Galassetti P, Davis SN, Wasserman DH. Glucoregulation during and after exercise in health and insulin-dependent diabetes. Exerc Sport Sci Rev 2005; 33: 17-23.

22 Ploug T, Galbo H, Richter EA. Increased muscle glucose uptake during contractions: no need for insulin. Am J Physiol 1984; 247: E726-31.

23 Coker RH, Kjaer M. Glucoregulation during exercise : the role of 55 the neuroendocrine system. Sports Med Auckl NZ 2005; 35: 575-83.

24 Coyle EF. Substrate utilization during exercise in active people. Am J Clin Nutr 1995; 61 (suppl 4): 968S-79S. 
25 Venables MC, Achten J, Jeukendrup AE. Determinants of fat oxidation during exercise in healthy men and women: a crosssectional study. J Appl Physiol 2005; 98: 160-67.

26 van Loon LJ, Greenhaff PL, Constantin-Teodosiu D, Saris WH, Wagenmakers AJ. The effects of increasing exercise intensity on muscle fuel utilisation in humans. J Physiol 2001; 536: 295-304.

27 Fahey AJ, Paramalingam N, Davey RJ, Davis EA, Jones TW, Fournier PA. The effect of a short sprint on postexercise whole-body glucose production and utilization rates in individuals with type 1 diabetes mellitus. J Clin Endocrinol Metab 2012; 97: 4193-200.

28 Harmer AR, Chisholm DJ, McKenna MJ, et al. High-intensity training improves plasma glucose and acid-base regulation during intermittent maximal exercise in type 1 diabetes. Diabetes Care 2007; 10 30: 1269-71.

29 Bally L, Laimer M, Stettler C. Exercise-associated glucose metabolism in individuals with type 1 diabetes mellitus. Curr Opin Clin Nutr Metab Care 2015; 18: 428-33.

30 Mallad A, Hinshaw L, Schiavon M, et al. Exercise effects on postprandial glucose metabolism in type 1 diabetes: a triple tracer approach. Am J Physiol Endocrinol Metab 2015; 308: E1106-15.

31 Frayn KN, Karpe F. Regulation of human subcutaneous adipose tissue blood flow. Int J Obes 2014; 38: 1019-26.

32 McAuley SA, Horsburgh JC, Ward GM, et al. Insulin pump basal adjustment for exercise in type 1 diabetes: a randomised crossover study. Diabetologia 2016; 59: 1636-44.

33 Tansey MJ, Tsalikian E, Beck RW, et al. The effects of aerobic exercise on glucose and counterregulatory hormone concentrations in children with type 1 diabetes. Diabetes Care 2006; 29: 20-25.

34 Riddell MC, Bar-Or O, Ayub BV, Calvert RE, Heigenhauser GJ. Glucose ingestion matched with total carbohydrate utilization attenuates hypoglycemia during exercise in adolescents with IDDM. Int J Sport Nutr 1999; 9: 24-34.

35 Al Khalifah RA, Suppère C, Haidar A, Rabasa-Lhoret R, Ladouceur M Legault L. Association of aerobic fitness level with exercise-induced hypoglycaemia in type 1 diabetes. Diabet Med 2016; 33: 1686-90.

36 Harmer AR, Chisholm DJ, McKenna MJ, et al. Sprint training increases muscle oxidative metabolism during high-intensity exercise in patients with type 1 diabetes. Diabetes Care 2008 31: 2097-102.

37 Singhvi A, Tansey MJ, Janz K, Zimmerman MB, Tsalikian E. Aerobic fitness and glycemic variability in adolescents with type 1 diabetes. Endocr Pract 2014; 20: 566-70.

38 Zander E, Bruns W, Wulfert P, et al. Muscular exercise in type I-diabetics. I. Different metabolic reactions during heavy muscular work in dependence on actual insulin availability. Exp Clin Endocrinol 1983; 82: 78-90.

39 Berger M, Berchtold P, Cüppers HJ, et al. Metabolic and hormonal effects of muscular exercise in juvenile type diabetics. Diabetologia 1977; 13: 355-65.

40 Yardley JE, Kenny GP, Perkins BA, et al. Resistance versus aerobic exercise: acute effects on glycemia in type 1 diabetes. Diabetes Care 2013; 36: 537-42.

41 Turner D, Luzio S, Gray BJ, et al. Impact of single and multiple sets of resistance exercise in type 1 diabetes. Scand J Med Sci Sports 2015 25: e99-109.

42 Guelfi KJ, Ratnam N, Smythe GA, Jones TW, Fournier PA. Effect of intermittent high-intensity compared with continuous moderate exercise on glucose production and utilization in individuals with type 1 diabetes. Am J Physiol Endocrinol Metab 2007; 292: E865-70.

43 Yardley JE, Kenny GP, Perkins BA, et al. Effects of performing resistance exercise before versus after aerobic exercise on glycemia in type 1 diabetes. Diabetes Care 2012; 35: 669-75.

44 Bally L, Zueger T, Buehler T, et al. Metabolic and hormonal response to intermittent high-intensity and continuous moderate intensity exercise in individuals with type 1 diabetes: a randomised crossover study. Diabetologia 2016; 59: 776-84.

45 Davey RJ, Paramalingam N, Retterath AJ, et al. Antecedent hypoglycaemia does not diminish the glycaemia-increasing effect and glucoregulatory responses of a $10 \mathrm{~s}$ sprint in people with type 1 diabetes. Diabetologia 2014; 57: 1111-18.

46 Teich T, Riddell MC. The enhancement of muscle insulin sensitivity after exercise: a Rac1-independent handoff to some other player? Endocrinology 2016; 157: 2999-3001.
147 Gomez AM, Gomez C, Aschner P, et al. Effects of performing morning versus afternoon exercise on glycemic control and hypoglycemia frequency in type 1 diabetes patients on sensor-augmented insulin pump therapy. J Diabetes Sci Technol 2015; 9: 619-24.

548 Turner D, Luzio S, Gray BJ, et al. Algorithm that delivers an individualized rapid-acting insulin dose after morning resistance exercise counters post-exercise hyperglycaemia in people with type 1 diabetes. Diabet Med 2016; 3: 506-10.

49 Tanenberg RJ, Newton CA, Drake AJ. Confirmation of hypoglycemia in the "dead-in-bed" syndrome, as captured by a retrospective continuous glucose monitoring system. Endocr Pract 2010; 16: 244-48.

50 Maran A, Pavan P, Bonsembiante B, et al. Continuous glucose monitoring reveals delayed nocturnal hypoglycemia after intermittent high-intensity exercise in nontrained patients with type 1 diabetes. Diabetes Technol Ther 2010; 12: 763-68.

51 Moser O, Tschakert G, Mueller A, et al. Effects of high-intensity interval exercise versus moderate continuous exercise on glucose homeostasis and hormone response in patients with type 1 diabetes mellitus using novel ultra-long-acting insulin. PloS One 2015; 10: e0136489.

52 Iscoe KE, Riddell MC. Continuous moderate-intensity exercise with or without intermittent high-intensity work: effects on acute and late glycaemia in athletes with type 1 diabetes mellitus. Diabet Med 2011; 28: 824-32.

2053 Kennedy A, Nirantharakumar K, Chimen M, et al. Does exercise improve glycaemic control in type 1 diabetes? A systematic review and meta-analysis. PloS One 2013; 8: e58861.

54 Adolfsson P, Mattsson S, Jendle J. Evaluation of glucose control when a new strategy of increased carbohydrate supply is implemented during prolonged physical exercise in type 1 diabetes. Eur J Appl Physiol 2015; 115: 2599-607.

2555 Rabasa-Lhoret R, Bourque J, Ducros F, Chiasson JL. Guidelines for premeal insulin dose reduction for postprandial exercise of different intensities and durations in type 1 diabetic subjects treated intensively with a basal-bolus insulin regimen (ultralente-lispro). Diabetes Care 2001; 24: 625-30.

56 Campbell MD, Walker M, Trenell MI, et al. Metabolic implications when employing heavy pre- and post-exercise rapid-acting insulin reductions to prevent hypoglycaemia in type 1 diabetes patients: a randomised clinical trial. PloS One 2014; 9: e97143.

57 Dubé M-C, Weisnagel SJ, Prud'homme D, Lavoie C. Is early and late post-meal exercise so different in type 1 diabetic lispro users? Diabetes Res Clin Pract 2006 ; 72: 128-34.

58 Kelly D, Hamilton JK, Riddell MC. Blood glucose levels and performance in a sports camp for adolescents with type 1 diabetes mellitus: a field study. Int J Pediatr 2010; 2010: 216167.

59 Graveling AJ, Frier BM. Risks of marathon running and hypoglycaemia in type 1 diabetes. Diabet Med 2010; 27: 585-88.

60 Galassetti P, Tate D, Neill RA, Richardson A, Leu S-Y, Davis SN. Effect of differing antecedent hypoglycemia on counterregulatory responses to exercise in type 1 diabetes. Am J Physiol Endocrinol Metab 2006; 290: E1109-17.

61 Riddell MC, Burr J. Evidence-based risk assessment and recommendations for physical activity clearance: diabetes mellitus and related comorbidities. Appl Physiol Nutr Metab 2011; 36 (suppl 1): S154-89.

62 American Diabetes Association. (4) Foundations of care: education nutrition, physical activity, smoking cessation, psychosocial care, and immunization. Diabetes Care 2015; 38 (suppl): S20-30.

63 Thomas DT, Erdman KA, Burke LM. Position of the Academy of Nutrition and Dietetics, Dietitians of Canada, and the American College of Sports Medicine: nutrition and athletic performance. J Acad Nutr Diet 2016; 116: 501-28.

64 Franc S, Daoudi A, Pochat A, et al. Insulin-based strategies to prevent hypoglycaemia during and after exercise in adult patients with type 1 diabetes on pump therapy: the DIABRASPORT randomized study. Diabetes Obes Metab 2015; 17: 1150-57.

65 Sawka MN, Burke LM, Eichner ER, Maughan RJ, Montain SJ, Stachenfeld, NS. Exercise and fluid replacement. Med Sci Sports Exerc 2007; 39: 377-90.

5566 Loucks AB, Kiens B, Wright HH. Energy availability in athletes. J Sports Sci 2011; 29 (suppl 1): S7-15. 
67 Frankenfield D, Roth-Yousey L, Compher C. Comparison of predictive equations for resting metabolic rate in healthy nonobese and obese adults: a systematic review. J Am Diet Assoc 2005; 105: 775-89.

68 Murphy CH, Hector AJ, Phillips SM. Considerations for protein intake in managing weight loss in athletes. Eur J Sport Sci 2015; 15: 21-8.

69 Phillips SM. Dietary protein requirements and adaptive advantages in athletes. Br J Nutr 2012; 108 (suppl 2): S158-167.

70 Phillips SM, Chevalier S, Leidy HJ. Protein "requirements" beyond the RDA: implications for optimizing health. Appl Physiol Nutr Metab 2016; 41: 565-72.

71 Mettler S, Mitchell N, Tipton KD. Increased protein intake reduces lean body mass loss during weight loss in athletes. Med Sci Sports Exerc 2010; 42: 326-37.

72 Shetty VB, Fournier PA, Davey RJ, et al. Effect of exercise intensity on glucose requirements to maintain euglycemia during exercise in type 1 diabetes. J Clin Endocrinol Metab 2016; 101: 972-80.

73 Hernandez JM, Moccia T, Fluckey JD, Ulbrecht JS, Farrell PA. Fluid snacks to help persons with type 1 diabetes avoid late onset postexercise hypoglycemia. Med Sci Sports Exerc 2000; 32: 904-10.

74 Beelen M, Burke LM, Gibala MJ, van Loon L JC. Nutritional strategies to promote postexercise recovery. Int J Sport Nutr Exerc Metab 2010; 20: 515-32.

75 van Albada ME, Bakker-van Waarde WM. Recurrent nightly ketosis after prolonged exercise in type 1 diabetes - the need for glycogen replacement strategies. Case report and review of literature. Pediatr Diabetes 2016; 17: 531-34.

76 Bracken RM, Page R, Gray B, et al. Isomaltulose improves glycemia and maintains run performance in type 1 diabetes. Med Sci Sports Exerc 2012; 44: 800-08.

77 Campbell MD, Walker M, Trenell MI, et al. A low-glycemic index meal and bedtime snack prevents postprandial hyperglycemia and associated rises in inflammatory markers, providing protection from early but not late nocturnal hypoglycemia following evening exercise in type 1 diabetes. Diabetes Care 2014; 37: 1845-53.

78 Perrone C, Laitano O, Meyer F. Effect of carbohydrate ingestion on the glycemic response of type 1 diabetic adolescents during exercise. Diabetes Care 2005; 28: 2537-38.

79 Burke LM. Re-examining high-fat diets for sports performance: did we call the "nail in the coffin" too soon? Sports Med Auckl NZ 2015; 45 (suppl 1): 33-49.

80 Burke LM, Hawley JA, Angus DJ, et al. Adaptations to short-term high-fat diet persist during exercise despite high carbohydrate availability. Med Sci Sports Exerc 2002; 34: 83-91.

81 Bartlett JD, Hawley JA, Morton JP. Carbohydrate availability and exercise training adaptation: too much of a good thing? Eur J Sport Sci 2015; 15: 3-12.

82 Paluska SA. Caffeine and exercise. Curr Sports Med Rep 2003; 2: 213-19.

83 Zaharieva DP, Miadovnik LA, Rowan CP, Gumieniak RJ, Jamnik VK, Riddell MC. Effects of acute caffeine supplementation on reducing exercise-associated hypoglycaemia in individuals with type 40 1 diabetes mellitus. Diabet Med 2016; 33: 488-96.

84 Mauvais-Jarvis F, Sobngwi E, Porcher R, et al. Glucose response to intense aerobic exercise in type 1 diabetes: maintenance of near euglycemia despite a drastic decrease in insulin dose. Diabetes Care 2003; 26: 1316-17

85 West DJ, Morton RD, Bain SC, Stephens JW, Bracken RM. Blood glucose responses to reductions in pre-exercise rapid-acting insulin for $24 \mathrm{~h}$ after running in individuals with type 1 diabetes. $J$ Sports Sci 2010; 28: 781-88.

86 Bracken RM, West DJ, Stephens JW, Kilduff LP, Luzio S, Bain SC. Impact of pre-exercise rapid-acting insulin reductions on ketogenesis following running in type 1 diabetes. Diabet Med 2011; 28: $218-22$.

87 West DJ, Stephens JW, Bain SC, et al. A combined insulin reduction and carbohydrate feeding strategy $30 \mathrm{~min}$ before running bes preserves blood glucose concentration after exercise through improved fuel oxidation in type 1 diabetes mellitus. J Sports Sci 2011 29: 279-89.

88 Campbell MD, Walker M, Bracken RM, et al. Insulin therapy and dietary adjustments to normalize glycemia and prevent nocturnal hypoglycemia after evening exercise in type 1 diabetes: a randomized controlled trial. BMJ Open Diabetes Res Care 2015; 3: e000085.
89 Arutchelvam V, Heise T, Dellweg S, Elbroend B, Minns I, Home PD. Plasma glucose and hypoglycaemia following exercise in people with type 1 diabetes: a comparison of three basal insulins. Diabet Med 2009; 26: 1027-32.

90 Heise T, Bain SC, Bracken RM, et al. Similar risk of exercise-related hypoglycaemia for insulin degludec to that for insulin glargine in patients with type 1 diabetes: a randomized cross-over trial. Diabetes Obes Metab 2016; 18: 196-99.

91 Heinemann L, Nosek L, Kapitza C, Schweitzer M-A, Krinelke L. Changes in basal insulin infusion rates with subcutaneous insulin infusion: time until a change in metabolic effect is induced in patients with type 1 diabetes. Diabetes Care 2009; 32: 1437-39.

1092 Diabetes Research in Children Network (DirecNet) Study Group. Prevention of hypoglycemia during exercise in children with type 1 diabetes by suspending basal insulin. Diabetes Care 2006; 29: $2200-04$

93 Admon G, Weinstein Y, Falk B, et al. Exercise with and without an insulin pump among children and adolescents with type 1 diabetes mellitus. Pediatrics 2005; 116: e348-55.

1594 Yardley JE, Iscoe KE, Sigal RJ, Kenny GP, Perkins BA, Riddell MC. Insulin pump therapy is associated with less post-exercise hyperglycemia than multiple daily injections: an observational study of physically active type 1 diabetes patients. Diabetes Technol Ther 2013; 15: 84-88.

95 Taplin CE, Cobry E, Messer L, McFann K, Chase HP, Fiallo-Scharer R. Preventing post-exercise nocturnal hypoglycemia in children with type 1 diabetes. J Pediatr 2010; 157: 784-88.e1.

96 Frier BM. Hypoglycaemia in diabetes mellitus: epidemiology and clinical implications. Nat Rev Endocrinol 2014; 10: 711-22.

97 Davey RJ, Howe W, Paramalingam N, et al. The effect of midday moderate-intensity exercise on postexercise hypoglycemia risk in individuals with type 1 diabetes. J Clin Endocrinol Metab 2013; 98: 2908-14.

98 Garg SK, Brazg RL, Bailey TS, et al. Hypoglycemia begets hypoglycemia: the order effect in the ASPIRE in-clinic study. Diabetes Technol Ther 2014; 16: 125-30.

99 Richardson T, Weiss M, Thomas P, Kerr D. Day after the night before: influence of evening alcohol on risk of hypoglycemia in patients with type 1 diabetes. Diabetes Care 2005; 28: 1801-02.

100 Chu L, Hamilton J, Riddell MC. Clinical management of the physically active patient with type 1 diabetes. Phys Sportsmed 2011; 39: 64-77.

101 Binek A, Rembierz-Knoll A, Polańska J, Jarosz-Chobot P. Reasons for the discontinuation of therapy of personal insulin pump in children with type 1 diabetes. Pediatr Endocrinol Diabetes Metab 2016; 21: 65-69.

102 Riddell MC, Milliken J. Preventing exercise-induced hypoglycemia in type 1 diabetes using real-time continuous glucose monitoring and a new carbohydrate intake algorithm: an observational field study. Diabetes Technol Ther 2011; 13: 819-25.

103 Adolfsson P, Ornhagen H, Jendle J. The benefits of continuous glucose monitoring and a glucose monitoring schedule in individuals with type 1 diabetes during recreational diving. J Diabetes Sci Technol 2008; 2: 778-84.

104 Bally L, Zueger T, Pasi N, Carlos C, Paganini D, Stettler C. Accuracy of continuous glucose monitoring during differing exercise conditions. Diabetes Res Clin Pract 2016; 112: 1-5.

105 Yardley JE, Sigal RJ, Kenny GP, Riddell MC, Lovblom LE, Perkins BA. Point accuracy of interstitial continuous glucose monitoring during exercise in type 1 diabetes. Diabetes Technol Ther 2013; 15: 46-49.

106 Davey RJ, Low C, Jones TW, Fournier PA. Contribution of an intrinsic lag of continuous glucose monitoring systems to difference in measured and actual glucose concentrations changing at variable rates in vitro. J Diabetes Sci Technol 2010; 4: 1393-99.

107 Taleb N, Emami A, Suppere C, et al. Comparison of two continuous glucose monitoring systems, Dexcom G4 Platinum and Medtronic Paradigm Veo Enlite System, at rest and during exercise. Diabetes Technol Ther 2016; 18: 561-77.

108 Adolfsson P, Strömgren A, Mattsson S, Chaplin J, Jendle J. Education and individualized support regarding exercise and diabetes improves glucose control and level of physical activity in type 1 diabetes individuals. J Endocrinol Diabetes Obes 2015; 3: 1071 [A: details correct?] 
109 Danne T, Tsioli C, Kordonouri O, et al. The PILGRIM study: in silico modeling of a predictive low glucose management system and feasibility in youth with type 1 diabetes during exercise. Diabetes Technol Ther 2014; 16: 338-47.

110 Riddell MC, Zaharieva DP, Yavelberg L, Cinar A, Jamnik VK. Exercise and the development of the artificial pancreas: one of the more difficult series of hurdles. J Diabetes Sci Technol 2015; 9: 1217-26.

111 Burke LM, Hawley JA, Wong SHS, Jeukendrup AE. Carbohydrates for training and competition. J Sports Sci 2011; 29 (suppl 1): S17-27.

112 Jeukendrup A. A step towards personalized sports nutrition: carbohydrate intake during exercise. Sports Med Auckl NZ 2014; 44 (suppl 1): S25-33.

113 Frid A, Ostman J, Linde B. Hypoglycemia risk during exercise after intramuscular injection of insulin in thigh in IDDM. Diabetes Care 1990; 13: 473-77.

114 Hirsch L, Byron K, Gibney M. Intramuscular risk at insulin injection sites--measurement of the distance from skin to muscle and rationale for shorter-length needles for subcutaneous insulin therapy. Diabetes Technol Ther 2014; 16: 867-73.

115 Hildebrandt P. Subcutaneous absorption of insulin in insulin-dependent diabetic patients. Influence of species, physico-chemical properties of insulin and physiological factors. Dan Med Bull 1991; 38: 337-46.

116 Rönnemaa T, Koivisto VA. Combined effect of exercise and ambient temperature on insulin absorption and postprandial glycemia in type I patients. Diabetes Care 1988; 11: 769-73.
1117 Peter R, Luzio SD, Dunseath G, et al. Effects of exercise on the absorption of insulin glargine in patients with type 1 diabetes. Diabetes Care 2005; 28: 560-65.

118 Bell KJ, Smart CE, Steil GM, Brand-Miller JC, King B, Wolpert HA Impact of fat, protein, and glycemic index on postprandial glucose control in type 1 diabetes: implications for intensive diabetes management in the continuous glucose monitoring era. Diabetes Care 2015; 38: 1008-15.

119 Breton MD, Kovatchev BP. Impact of blood glucose self-monitoring errors on glucose variability, risk for hypoglycemia, and average glucose control in type 1 diabetes: an in silico study. J Diabetes $\mathrm{Sci}$ Technol 2010; 4: 562-70.

10120 Tonyushkina K, Nichols JH. Glucose meters: a review of technical challenges to obtaining accurate results. J Diabetes Sci Technol 2009; 3: $971-80$.

121 Castle JR, Jacobs PG. Nonadjunctive Use of continuous glucose monitoring for diabetes treatment decisions. J Diabetes Sci Technol 2016; 10: 1169-73.

122 Blaak E. Sex differences in the control of glucose homeostasis. Curr Opin Clin Nutr Metab Care 2008; 11: 500-04.

123 Deane AM, Horowitz M. Dysglycaemia in the critically illsignificance and management. Diabetes Obes Metab 2013 15: 792-801.

124 Campbell MD, Walker M, Trenell MI, et al. Large pre- and postexercise rapid-acting insulin reductions preserve glycemia and prevent early- but not late-onset hypoglycemia in patients with type 1 diabetes. Diabetes Care 2013; 36: 2217-24. 